Paper ID \#19870

\title{
Closing the Gap: Using Supplemental Instruction as a Tool to Assist Minori- ties in Engineering
}

\section{Lt. James Blake Gegenheimer, STEP}

James Gegenheimer is an MSME Candidate in Mechanical Engineering at LSU. James is a Second Lieutenant in the United States Air Force. He will be stationed at Hill Air Force Base in Salt Lake City, Utah. He plans to pursue a Ph.D. through the Air Force and work with the Air Force Weapons Research Laboratory. James is currently the Supplemental Instruction Coordinator at LSU for the College of Engineering. He also served as a Supplemental Instructor in Thermodynamics for over three years. He has worked to improve how STEM college students learn through the use of active learning.

\section{Mr. Charles Algeo Wilson IV, Louisiana State University}

Charles is a PhD student in Environmental Sciences at Louisiana State University. In 2012, he earned his master's degree in Medical and Health Physics and has since been working towards a PhD. During his studies, he has worked actively with the LSU STEM Talent and Expansion Program and LSU Center for Academic Success helping with different methods that aim to improve how STEM college students learn including tutorial centers, PLTL, SI, and recitation programs.

\section{Adrienne Steele, Louisiana State University}

Adrienne Steele has over 18 years experience in STEM education. Currently, Adrienne works at Louisiana State University, managing all aspects of the STEP project that consists of a large-scale peer mentoring program in the College of Engineering. Previously, she founded and coordinated the Scope-On-A-Rope Outreach Program (SOAR) in the Department of Biological Sciences, where she worked for 10 years. Prior to her positions at LSU, Adrienne was the Science Education Curator at the Louisiana Art and Science Museum in Baton Rouge. Adrienne has a Master of Science degree in zoology from LSU, where she studied in the Museum of Natural Science collections, and an Education Specialist Certification in science education.

\section{Dr. Warren N. Waggenspack Jr., Louisiana State University}

Warren N. Waggenspack, Jr. is currently the Undergraduate Program Director and holder of the Ned Adler Professorship in Mechanical Engineering at Louisiana State University. He obtained both his baccalaureate and master's degrees from LSU ME and his doctorate from Purdue University's School of Mechanical Engineering. He has been actively engaged in teaching, research and curricula development since joining the LSU faculty in 1988. As Associate Dean in the College of Engineering (2004-2014), he acquired significant funding from NSF to support the development of several initiatives aimed at improving student retention and graduation rates as well as supporting faculty with development of effective learning and teaching pedagogies. 


\section{Closing the Gap: Using Supplemental Instruction as a Tool to Assist Minorities in Engineering}

\section{Abstract}

Supplemental Instruction (SI), an active learning module in which undergraduate students hold optional sessions outside of lecture, has been shown to have great success at the College of Engineering (CoE) at Louisiana State University (LSU) when implemented into large enrollment courses that have a high likelihood of the student receiving a D, F or W. Previous research has shown that SI gives significant benefit to all students who participate, including above average and students from underrepresented groups. Minority students often face disadvantages when taking these courses due to a weaker educational background or sense of belonging. Programs that are inclusive of all diversity groups have been successful in raising the performance of atrisk students to the same level as their peers. Combining active learning into these programs can have further benefits as well; this has been shown by the U.S. Department of Education, Redish and Longfellow. The goal of this research is to study the effects of SI and how this program may impact minority students, who make up $16.2 \%$ of the student population. Without incentivizing students, the SI program at LSU has found that ethnic minority students (defined here as AfricanAmerican, Hispanic and Asian) have utilized SI more than Caucasian students. Students from all minority groups who do not participate in SI have a lower chance of passing a course than Caucasian students with no attendance in SI sessions, but as attendance increases, the gap between passing rates steadily decreases to a statistically indistinguishable amount for Hispanic and Asian students. Although African-American students continue to underperform compared to Caucasian students with SI attendance, they show the largest gains in passing rates of any group (34\% increase). Further analysis between genders and socioeconomic status found that female and low-socioeconomic students attend sessions at a slightly higher rates than males and students of high-socioeconomic status. Females perform higher with regular session attendance, whereas they perform near equal to that of males with no session attendance. It was found that lowsocioeconomic students underperform with no session attendance with the gap closing to within $2.8 \%$ of course passing rates once attending SI regularly. Although this program has been shown to positively impact engineering course success for all students in LSU's CoE, it is clear that SI is even more beneficial for underrepresented groups. SI is in essence closing the gap for minority students by helping them to overcome academic hurdles in an open, non-discriminatory environment.

\section{Background}

The development of programs designed to increase the success of minority students in engineering has become an important topic in recent years. Many questions arise that point to one theme: what can we do to bridge the gap found among minority students?

There are a multitude of programs and organizations designed to increase the success of minority students at engineering colleges across the US, such as the Society of Women Engineers, Society of Hispanic Professional Engineers, and National Society of Black Engineers. Summer bridge camps and similar programs that help increase students' academic preparation in mathematics have also been beneficial for underrepresented students ${ }^{(1,2)}$. At Louisiana State 
University (LSU), we provide a program that offers a potential solution to bridging the gap for minority students-Supplemental Instruction.

Supplemental Instruction (SI) offers additional help to students through peer interaction. Students who have succeeded with high marks in traditionally difficult classes are chosen to hold weekly review sessions where they cover course material and help students connect theory and problem solving, a traditional obstacle students face in engineering courses. Supplemental Instructors (SIs) are trained in active learning techniques and other pedagogical methods, which have been shown to increase students' performance ${ }^{(3,4,5)}$. SIs also attend course lectures, hold office hours, participate in weekly meetings, and communicate regularly with the course instructor. A highlight of the SI program is that it provides a comfortable, non-punitive environment for learning from an experienced peer. Previous analyses of the SI program at LSU have shown that students who regularly attend SI are $23.2 \%$ more likely to pass the course compared to students who do not attend SI (updated with new data from previous publication) ${ }^{(4)}$. It has also been shown that there is no observable self-selection bias in the data; i.e. it's not just "good students" who go to SI sessions, and all students benefit from participating regardless of their academic preparation ${ }^{(4,5)}$.

There are many different groups of students who are underrepresented in engineering fields. Three demographic variables were chosen for this study based on available data from university records: ethnicity, gender, and socioeconomic status. Students in the College of Engineering at LSU are $70.6 \%$ Caucasian and $80 \%$ male, leaving reasonable concern as to whether minority groups are participating at the same level as their Caucasian male counterparts.

\subsection{The Ethnic Minority}

The first subpopulation of students examined were those who identify as a member of one of three ethnic minorities: African-American, Hispanic, or Asian. While Asians aren't considered an underrepresented group in engineering, they were included in these analyses as an ethnic minority as to not infer that they are more successful than other students. AfricanAmerican and Hispanic students show similar interest in pursuing STEM degrees as Caucasian students while attending high school and are entering into these fields across the United States at similar rates through their representation in the populace, while Asian students tend to show higher rates of interest in STEM degrees ${ }^{(6,7)}$. However, these students are two-thirds less likely to persist in STEM compared to Caucasian students, indicating the presence of a barrier that is impeding these students from graduating in these fields ${ }^{(8)}$. According to the US Commission on Civil Rights, success in engineering is heavily dependent on a student's academic knowledge upon entering college ${ }^{(6)}$. However, the author also makes a strong point that absolute preparation is not the only factor; relative preparation can also be crucial. If students feel that their prerequisite knowledge is lesser than that of their peers, this can easily discourage them and make them more likely to leave engineering. Though these factors are true for all students, they are particularly troublesome for minorities, as they often have lesser academic preparation for highly advanced degrees such as engineering ${ }^{(6)}$. 


\subsection{The Female Minority}

Similar to the ethnic minorities, mathematical ability did not seem to be a significant factor for females in choosing a degree path ${ }^{(7)}$. However, females were not as likely to choose engineering as a degree as minority students ${ }^{(9,10)}$. At LSU, only $22 \%$ of incoming engineering freshmen are female even though females account for over half of the university's population. Once in engineering, though, female students persist at a much greater rate than ethnic minorities, falling only $3 \%$ lower than males at LSU. The same confidence issues that ethnic minorities feel might explain this small decrease. The stigma that engineering is a male dominated career field can subconsciously affect female students by reducing their confidence and self-efficacy, and a correlation clearly exists between self-efficacy and success in STEM fields ${ }^{(11,12)}$.

\subsection{The LSES Minority}

Students of low socioeconomic status (LSES) have to overcome many barriers to getting an education that other students do not face. These students are often solely responsible for paying their own way through college, having to work full-time jobs while taking a full load of difficult classes. These students often have additional financial burdens that can make the path to an engineering degree particularly daunting. Due to these factors and more, LSES students are less likely to attempt a STEM degree program following high school graduation ${ }^{(14,15,16,17)}$. The American Association for University Women found that socioeconomic differences outweighed gender differences in overall performance in and leading to college ${ }^{(18)}$. Although LSES students tend to have greater financial motivation to attain a university degree than their peers, studies have found no significant difference in persistence between these and other students in engineering ${ }^{(14,19)}$. Donaldson's study also found that there was little difference between these students with respect to confidence.

\section{Methods}

The SI program's first model for determining success was to compare the number of sessions attended $\left(0,1-3\right.$, and 4 or more) with the course passing rates ${ }^{(4)}$. In this study, as with previous research by the authors, session attendance was recorded using sign in sheet during each session, and course passing rates were normalized by subtracting overall course passing rates from each student's pass or fail rate, allowing for the ability to make broad statements regarding the efficacy of the program overall. This allows student performance in classes with higher DFW rates (percentage of students earning a D, F, or W) to be more accurately compared to classes with lower DFW rates. It was later determined that the session attendance designations of $0,1-3$, and 4 or more were arbitrary-course performance steadily increased as percent attendance increased ${ }^{(5)}$. For ease of comparison, students were placed into bins of $0 \%, 1-33 \%$, or $34 \%-100 \%$ attendance, with the latter used to represent regular attendance in SI. As further analyses of the program were conducted, predictors such as Math ACT were used to determine if the student was more likely to succeed regardless of their attendance in SI ${ }^{(5)}$. It was determined that students with lower Math ACT scores were more likely to attend SI sessions and that all students benefit from regular attendance regardless of academic preparation. All of these analyses were repeated for this study, separating students into subpopulations based on ethnicity, gender, and socioeconomic status. 
In order to determine if the SI program at LSU is successful in helping different subpopulations of students, data were collected from the university registrar for all students who have taken one of the courses in which engineering SI was offered since Spring 2013 $(n=17,698)$. This data set included students' gender, ethnicity, family income contribution from the FAFSA (used to estimate socioeconomic status), and Math ACT scores (used to evaluate academic preparation). A total of 10,414 student visits were recorded in engineering SI sessions from Spring 2013 through Summer 2016; these are not unique students, as a student is counted separately for each course in which they were enrolled and SI was offered.

Three major ethnic groups were included in these analyses: African-American, Hispanic, and Asian. American Indians, Pacific Islanders, and Alaskan Natives were not included due the very small population sizes of these groups at LSU. Students with unknown racial designation $(\mathrm{n}=711)$ as well as those who self-reported as more than one race (multiracial) and foreign students (non-resident aliens) were not included since their specific racial makeup was unknown. Figure 1 shows the breakdown of students' ethnicities in the data set. A student's gender was indicated to be male or female, as designed in the registrar's system. The FAFSA was used to determine socioeconomic status as defined by the US Department of Education ${ }^{(20)}$. For example, for a family of four, the low socioeconomic status (LSES) is defined as a net income of $\$ 36,450$ or less. It was impossible to determine a student's family size, so students with a FAFSA of less than $\$ 36,450$ were marked at LSES in the dataset.

To get the big picture of how SI is affecting separate minority groups, the authors performed similar analyses to previous works, this time subdividing students into separate demographic categories ${ }^{(4,5)}$. Separate analyses were conducted for each minority demographic (ethnicity, gender, socioeconomic status). These analyses include: overall utilization of SI by minority groups, course passing rates compared to SI attendance, and academic preparation (defined by Math ACT score) as it relates to attendance and passing rates ${ }^{(5,15)}$.

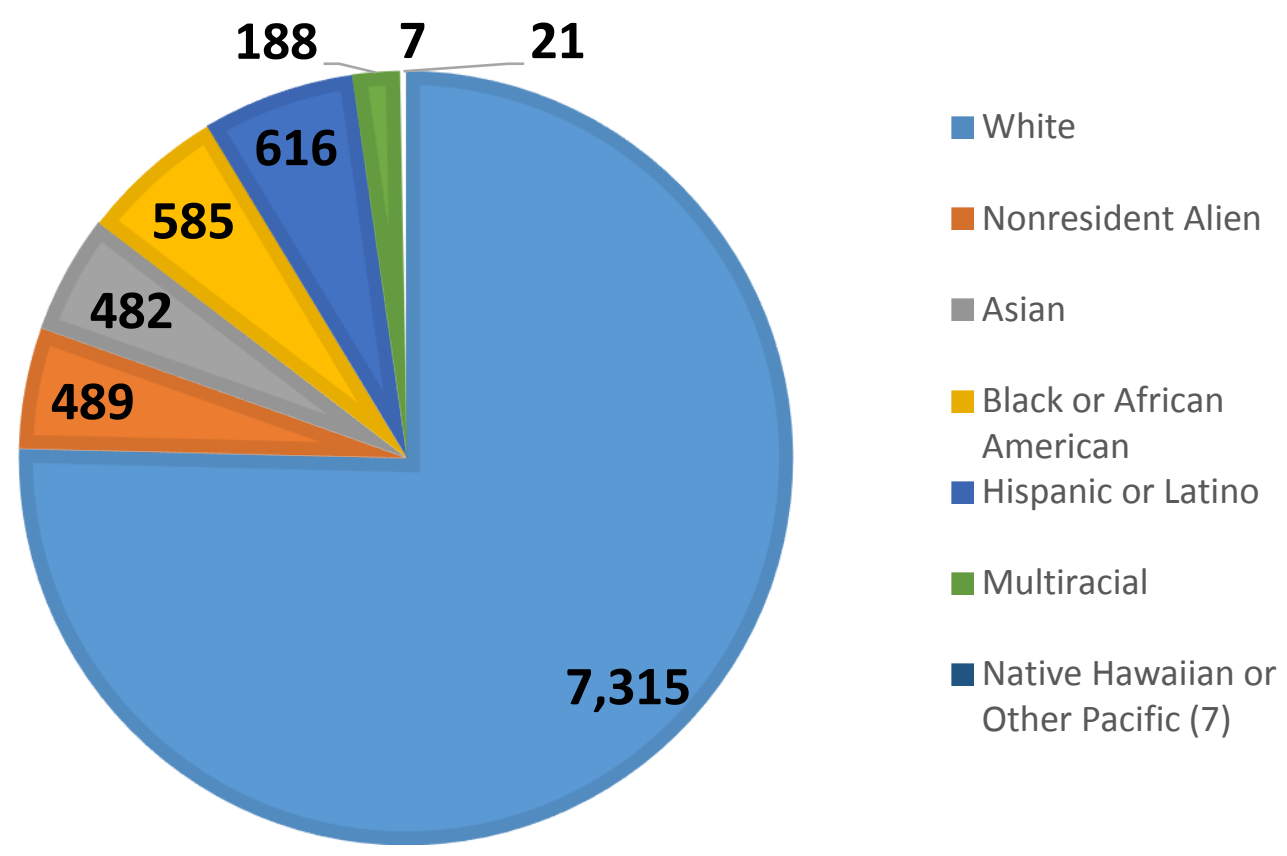

Figure 1 - Racial Composition of Students in Data Set 


\section{Results}

\subsection{The Ethnic Minority}

The first question was whether or not minority groups are utilizing SI to the same degree. Figure 2 shows the relative percent of students in each ethnic group who attended SI sessions. The session attendance was divided into three bins: 0\%, 1-33\%, and 34-100\%. AfricanAmerican, Hispanic and Asian students attend SI at least 5\% more often than Caucasian students.

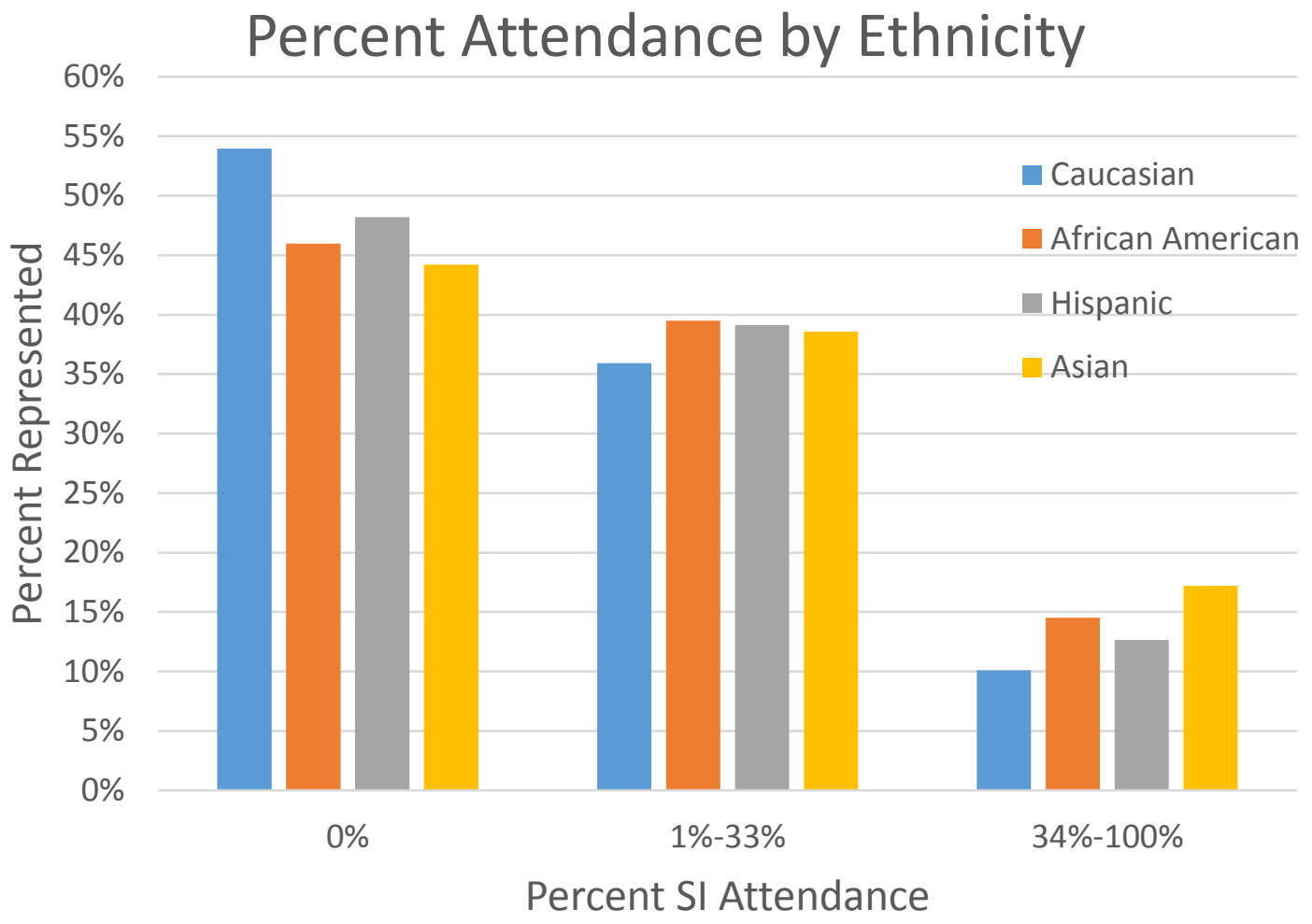

Figure 2 - Percent Attendance in SI for Ethnic Minority Students

Normalized course passing rates were then compared to SI session attendance for each group. As seen in Figure 3, African-American students perform lower overall than the other ethnic groups. This is especially apparent for students who did not participate in SI, as AfricanAmericans were $23 \%$ less likely to pass a course than Caucasian students without this intervention. However, with session attendance approaching $100 \%$, the performance gap is reduced to half of that value with a difference of $12 \%$. Meanwhile, Asian and Hispanic students also begin at a lower passing rate than Caucasian students without attendance in SI, but outperform them as attendance increases. The large amount error seen in the high attendance bins is due to decrease in sample size, as few students attend $80-100 \%$ of SI sessions. For example, there are only 51 students represented in the $90.01 \%-100 \%$ bin, but 5,440 students represented in the $0 \%$ bin. Larger attendance bins were created to increase the sample sizes, with participation divided into no attendance (0\%), low attendance (1-33\%), and regular attendance (34-100\%), as shown in Figure 4. 


\section{Passing Rates for Ethnic Minority Students}

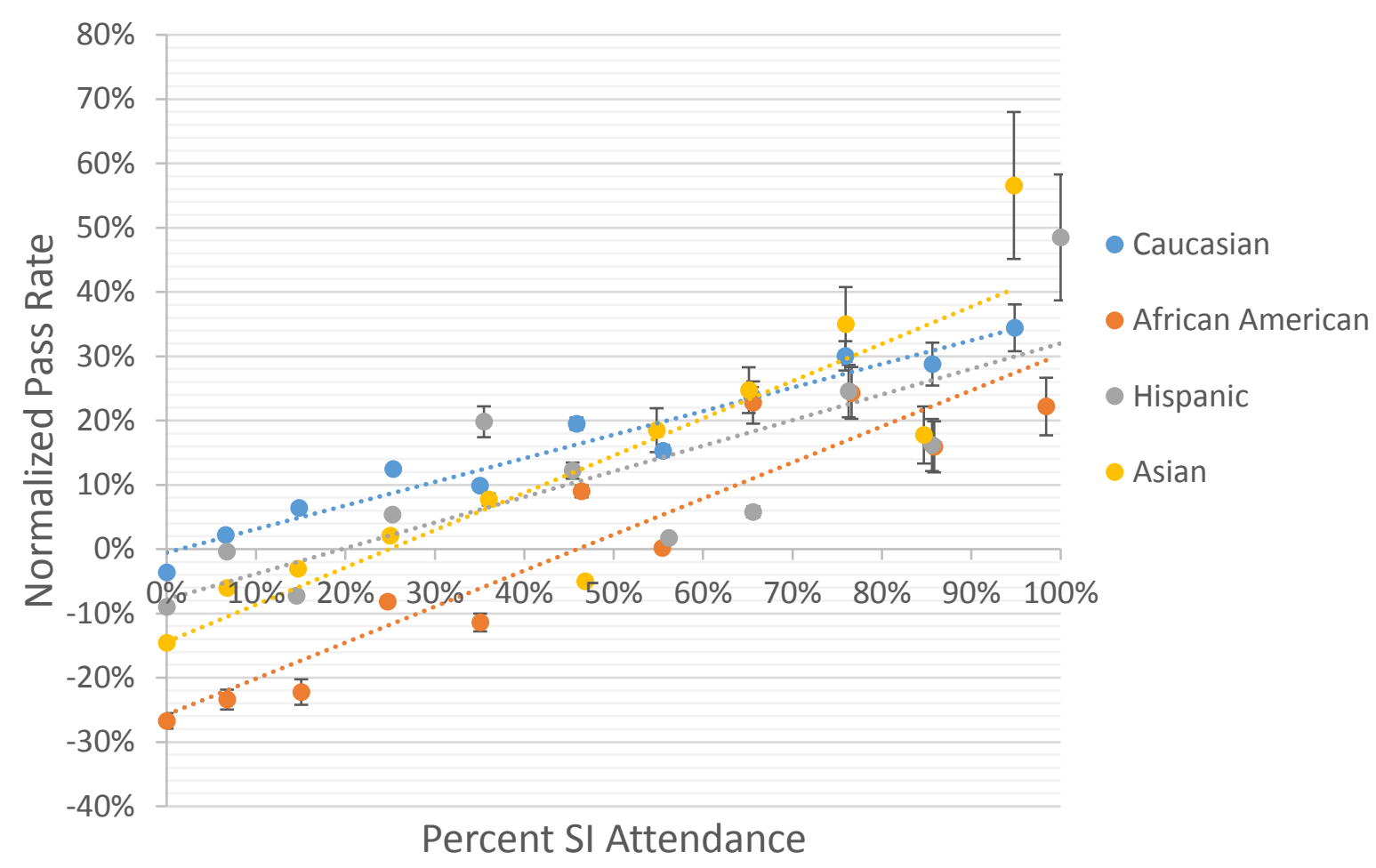

Figure 3 - Passing Rates for Ethnic Minority Students with SI Attendance

It is easier to see in Figure 4 that all students follow the same trend of improving their passing rates with increased session attendance. Asian and Caucasian students have essentially the same passing rates when regularly attending SI, with Hispanic students only behind them by 1.4\%. Although African-American students are not passing at a rate as high as the other groups, their performance gap is greatly reduced. It is important to note that African-American students made the largest gains in course performance, going from $26.7 \%$ less likely to pass a course to $7.7 \%$ more likely to pass, a difference of $34.4 \%$. 


\section{Passing Rates for Ethnic Minority Students}

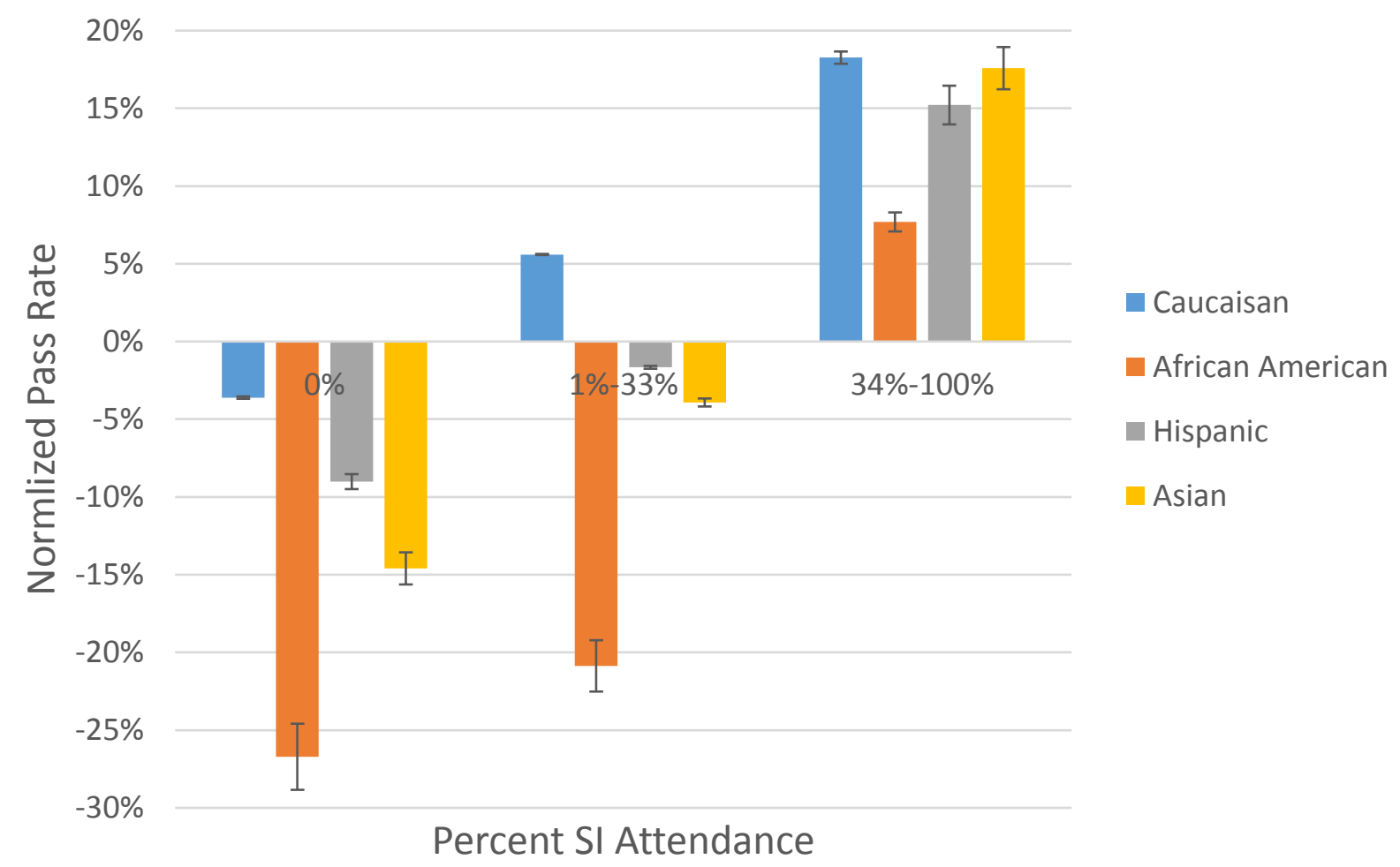

Figure 4 - Passing Rates for Ethnic Minority Students in \% Bins of SI Attendance

An additional question remains regarding whether only the best students are attending and benefitting from SI. Figures 5, 6, 7 and 8 show students' passing rates subdivided into Math ACT bins with the same three subdivisions of SI attendance $(0 \%, 1-33 \%, 34-100 \%)$. The bins for MACT were chosen to create equal groups of students, although many groupings have large error due to the lower bin sizes. Though the statistical significance is weakened due a higher quantity of bins, the trend of increased passing rates with session attendance holds true for each minority group. For African-American students, all groups that regularly attend SI are performing above the course average to varying degrees. It is surprising, however, that these students who have performed highly on the MACT (30-36) are 6.2\% below the course average with no SI attendance. This can indicate that a student's academic index prior to entering engineering might not be as crucial as the literature states ${ }^{(6)}$. Hispanic students seem to follow a similar trend as Caucasian students, although students who attended SI regularly with the lowest MACT scores did not improve their passing rates as much. Asian students show an interesting trend where no matter how much they were academically prepared for a STEM degree, they seem to underperform without SI attendance. The pattern for Caucasian students differs from all minority groups in that they perform equally well with regular SI attendance regardless of their MACT scores. 


\section{Caucasian Passing Rates by MACT}

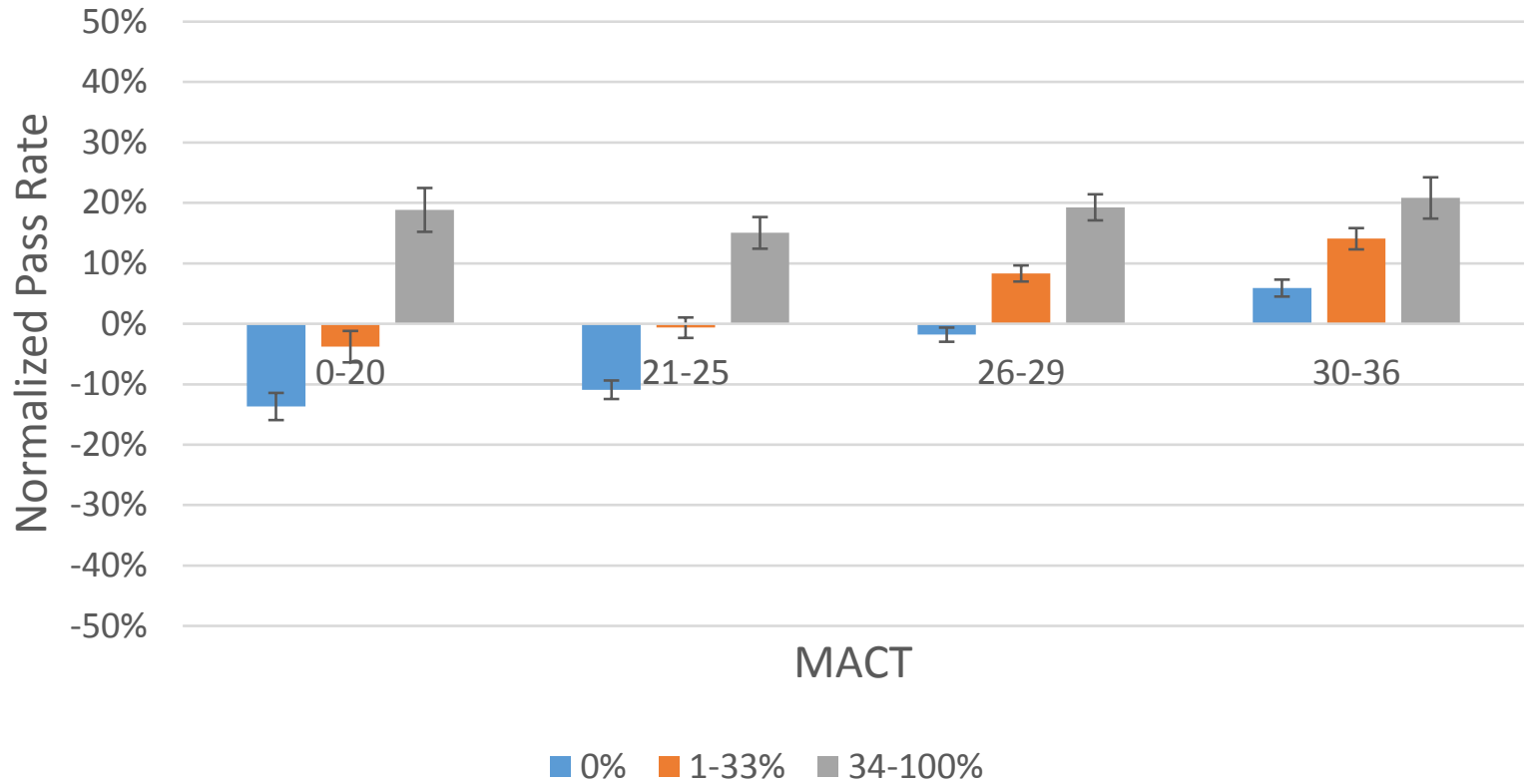

Figure 5 - Passing Rates for Caucasian Students with SI Attendance by Math ACT

\section{African American Passing Rates by MACT}

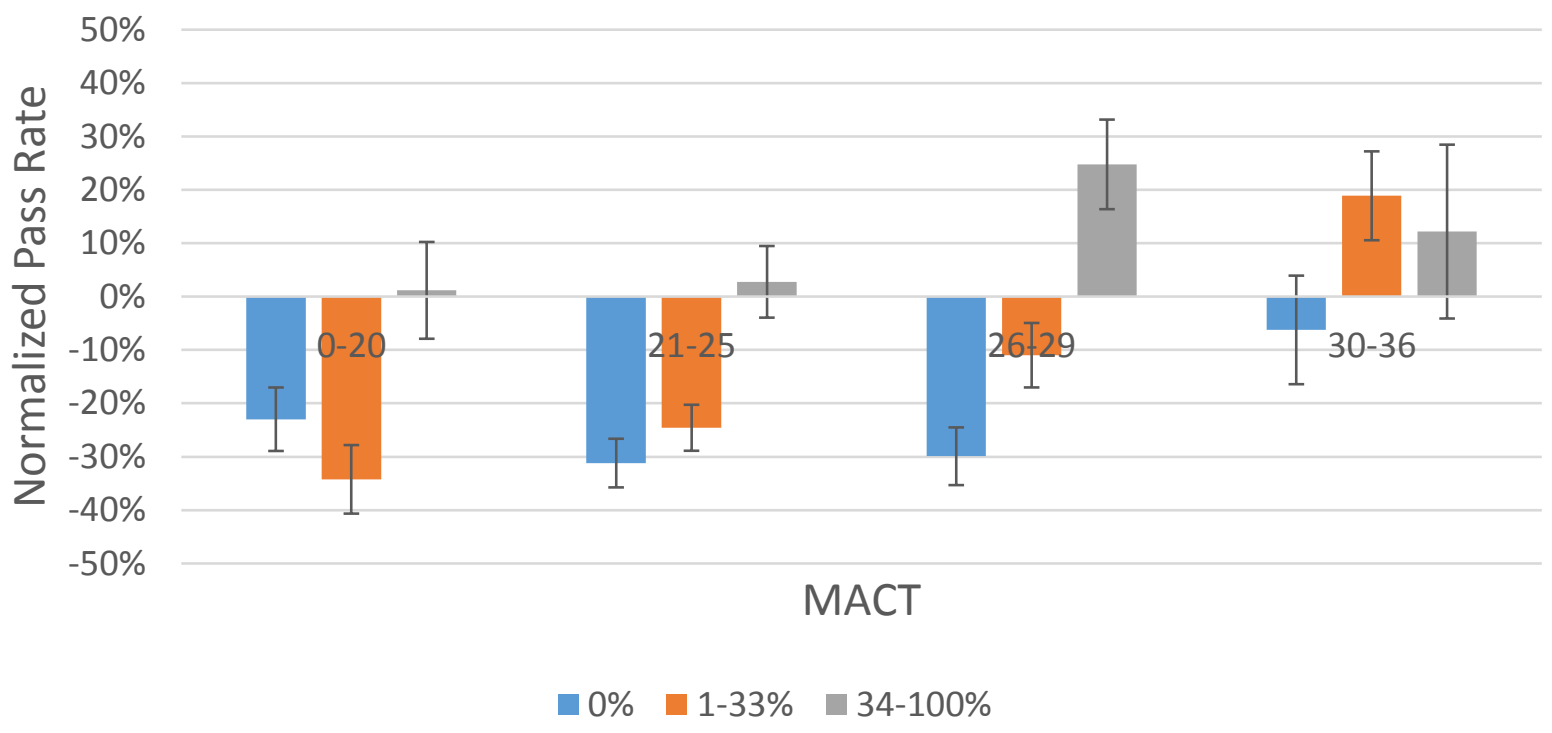

Figure 6 - Passing Rates for African American Students with SI Attendance by Math ACT 


\section{Hispanic Passing Rates by MACT}

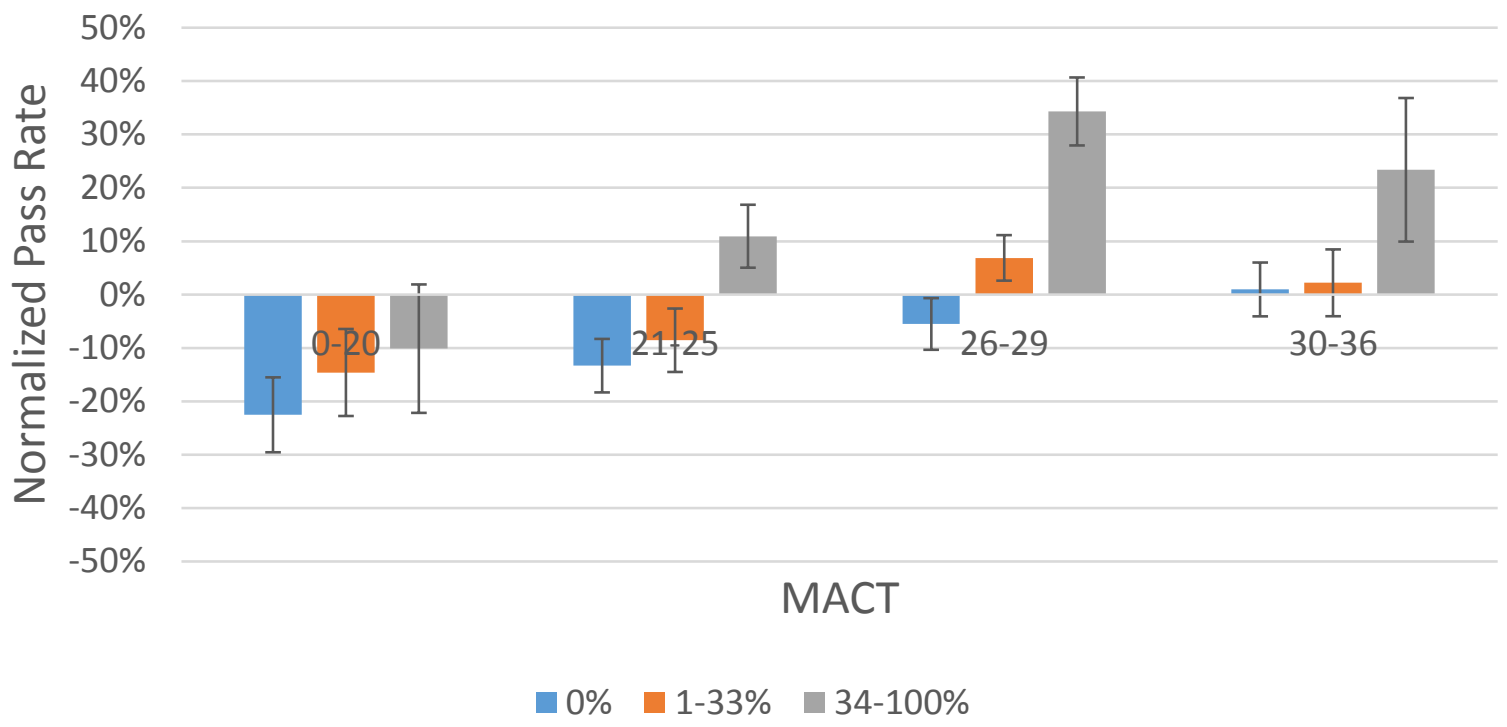

Figure 7 - Passing Rates for Hispanic Students with SI Attendance by Math ACT

\section{Asian Passing Rates by MACT}

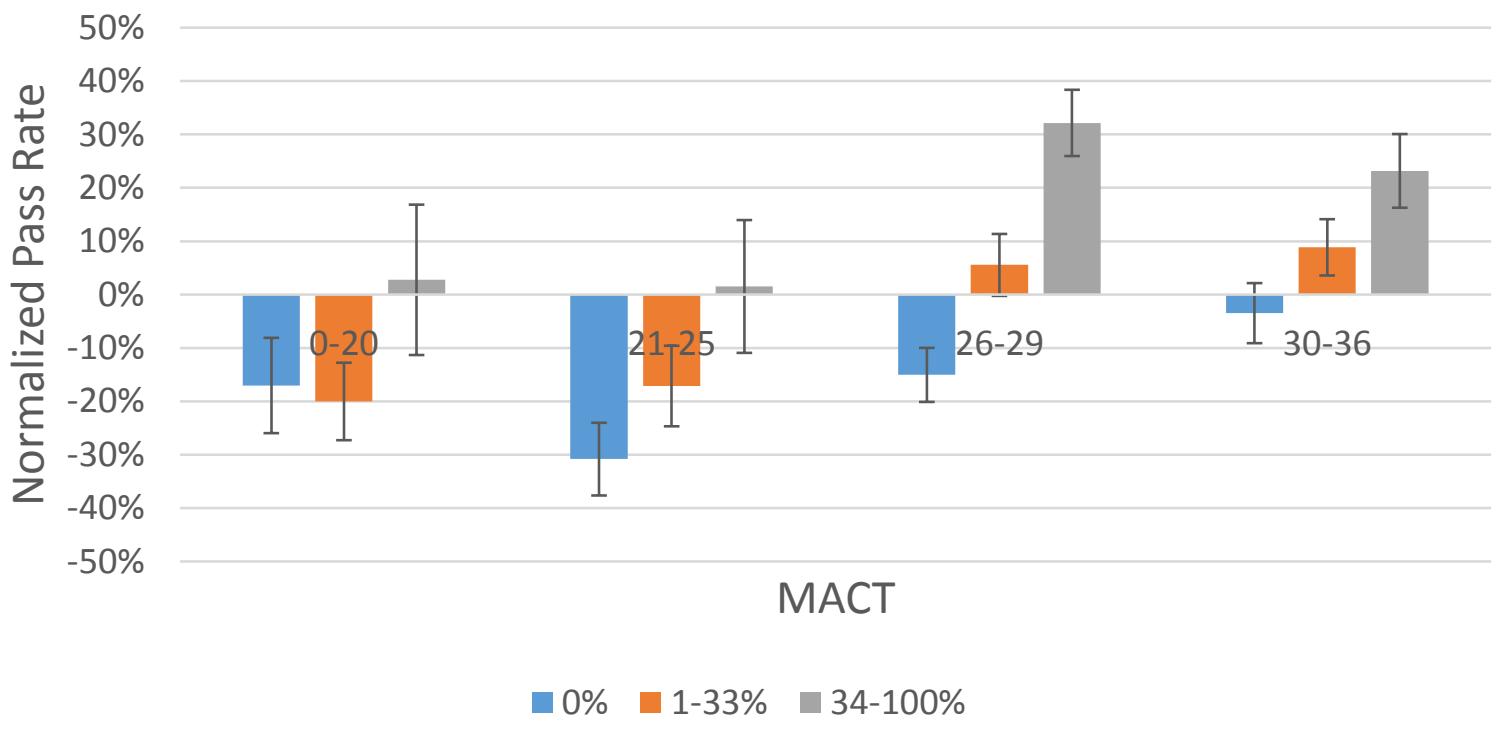

Figure 8-Passing Rates for Asian Students with SI Attendance by Math ACT

\subsection{The Female Minority}

Gender differences were examined next, repeating the same analyses that were conducted with ethnic groups. Similarly to what was observed in Figure 2 for ethnic minorities, females are utilizing SI slightly more than male students (Figure 9). 


\section{Percent Attendance by Gender}

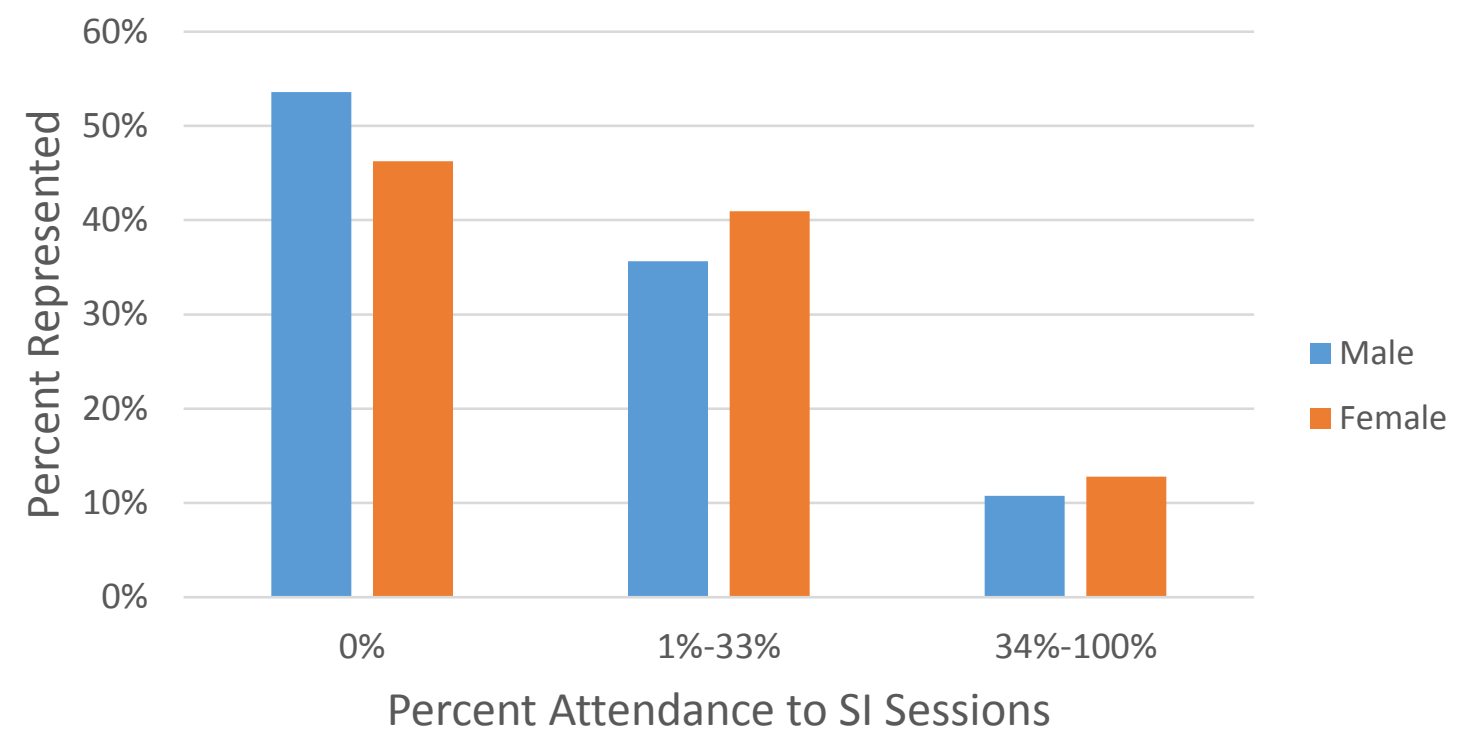

Figure 9 - Percent Attendance for Female Students

However, passing rates were much different for females than other minority groups. Males and females not attending SI have only a $1.4 \%$ difference in passing the course, which can be argued as insignificantly small. Unlike the Figure 3, Figure 10 has multiple jumps making larger bin sizes (Figure 11) necessary. Figure 11 better illustrates the increase in passing rates for female students who regularly utilize SI. As with ethnic minorities, the general trend remains apparent-both males and females are performing better than their peers when participating in SI. 


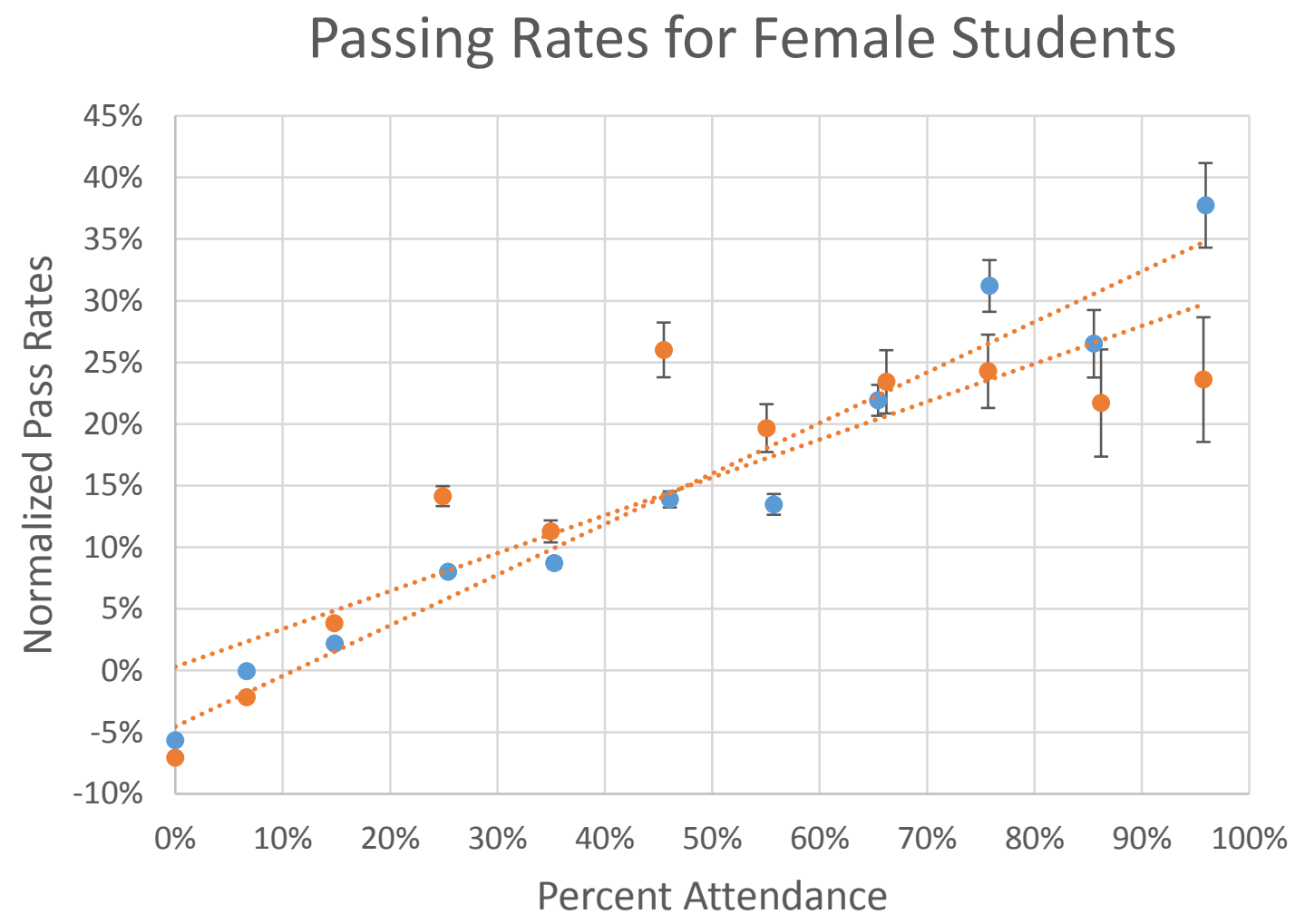

- Males

- Females

Figure 10 - Passing Rates for Female Students

\section{Passing Rates for Female Students}

$25 \%$
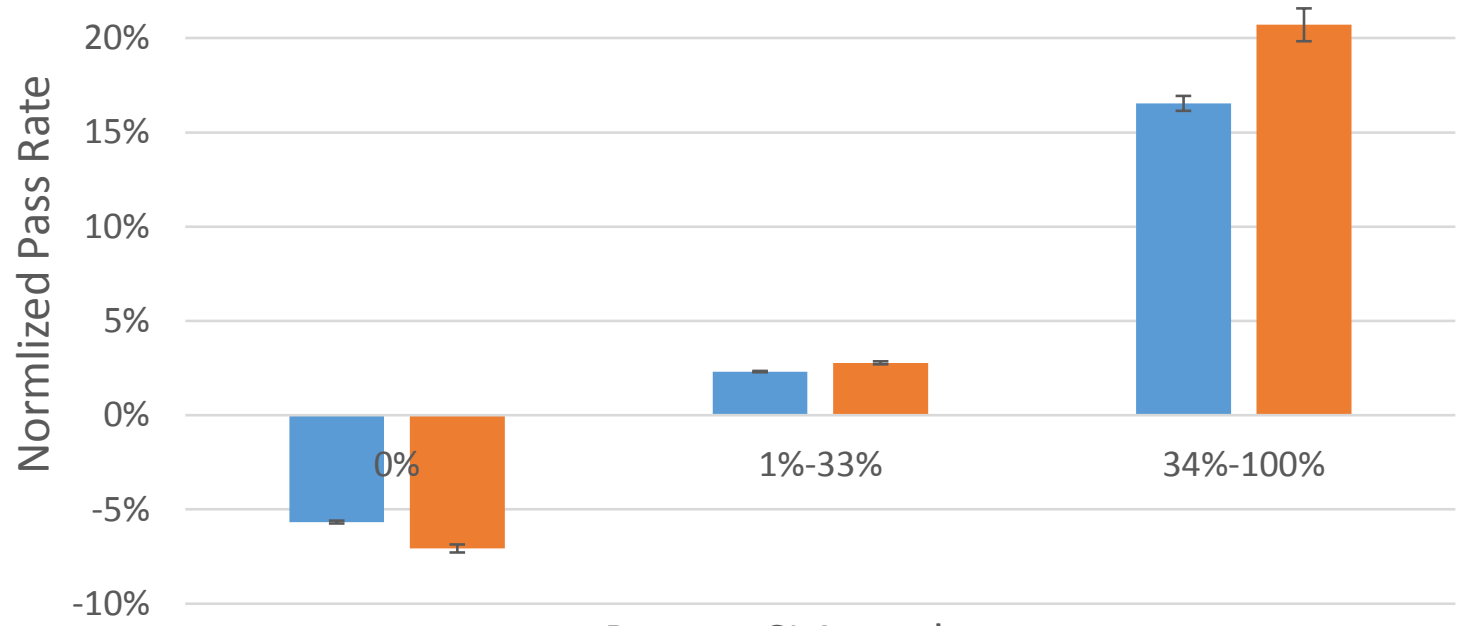

\section{Percent SI Attendance}

Figure 11 - Passing Rates for Female Students in \% Bins of SI Attendance 
Unlike the plots for ethnic minority groups, greater subdivisions of MACT scores were used due to the larger amount of students in each bin, thereby increasing the resolution. For female students, the trends in passing rates fall closer to males than ethnic minorities do to Caucasian students. The interesting difference here is the point at which females begin to outperform males. In Figure 11, it was shown that females began outperforming males at higher session attendance, but it seems that the academic index may play a factor as well. Independent of SI attendance, males outperform females in the MACT range of 0-26 while no statistical difference is found in the 27-28 range. Once females have a 29 MACT score or higher, they outperform males substantially in all categories.

\section{Female Passing Rates by MACT}

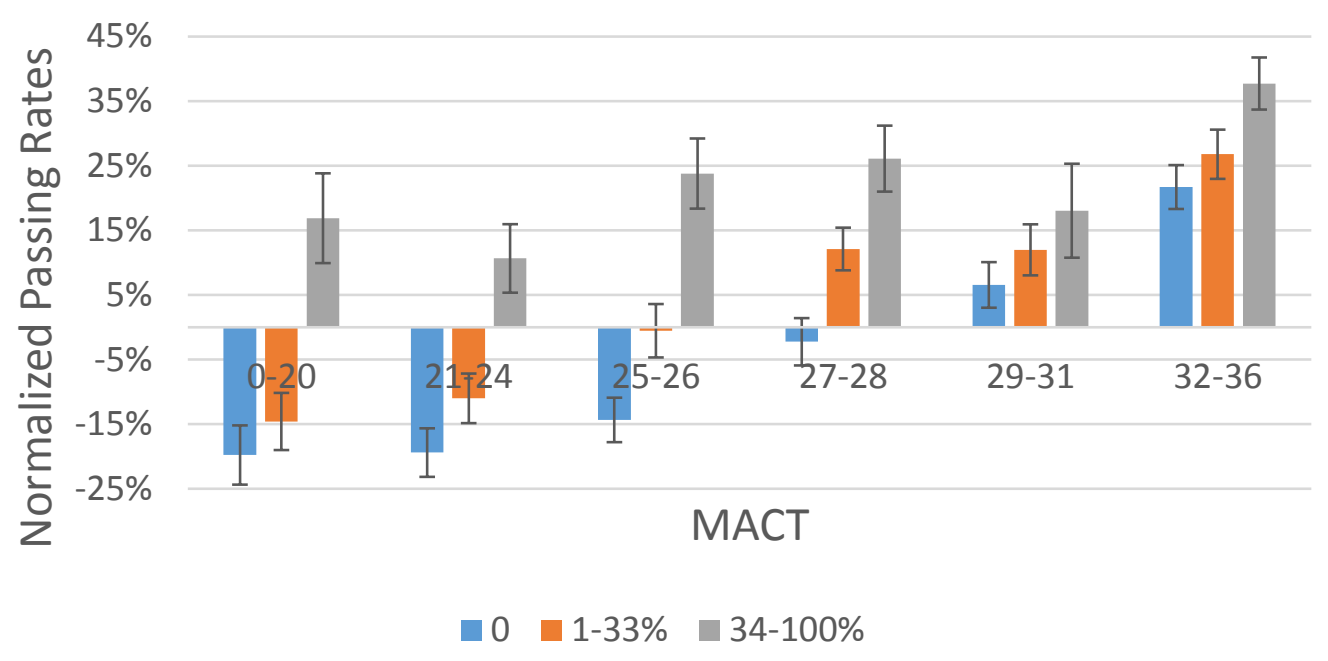

Figure 12 - Passing Rates for Female Students with SI Attendance by Math ACT

\section{Male Passing Rates by MACT}

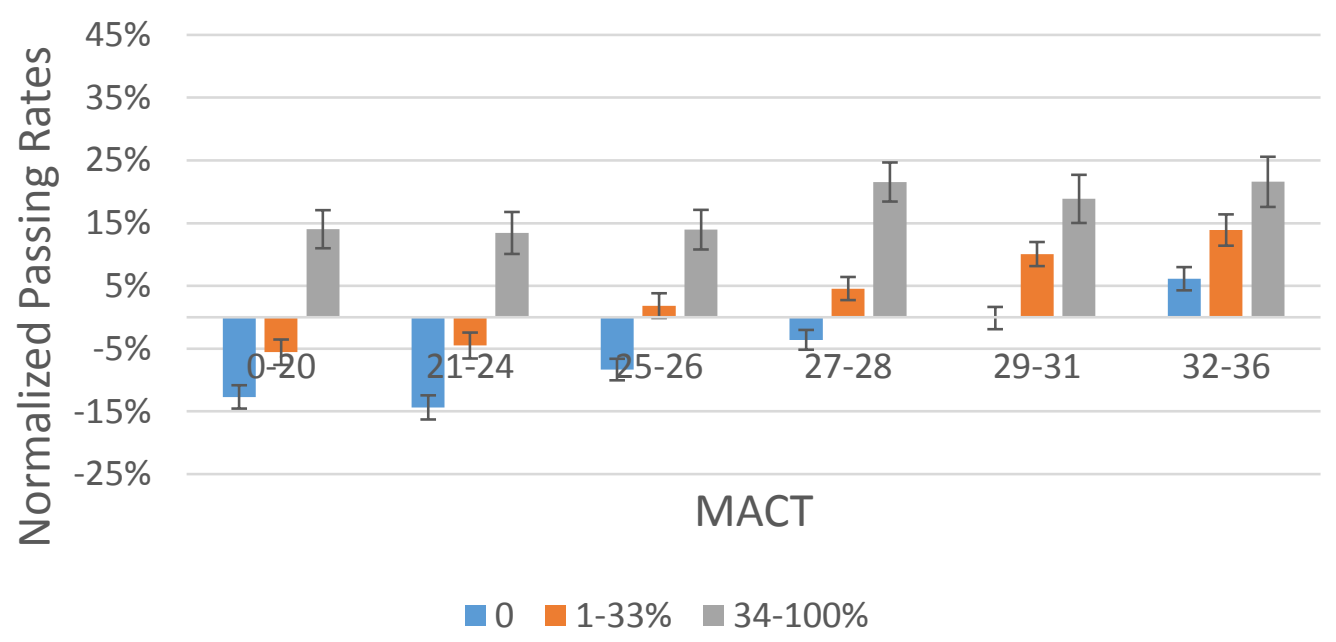

Figure 13 - Passing Rates for Male Students with SI Attendance by Math ACT 


\subsection{The LSES Minority}

Analyses were performed once again, using socioeconomic status to group students. Unlike other minority groups there is not a significant difference between the percent of students with low-socioeconomic status (LSES) utilizing SI compared to other students (Figure 14).

\section{Percent Attendance for LSES Students}

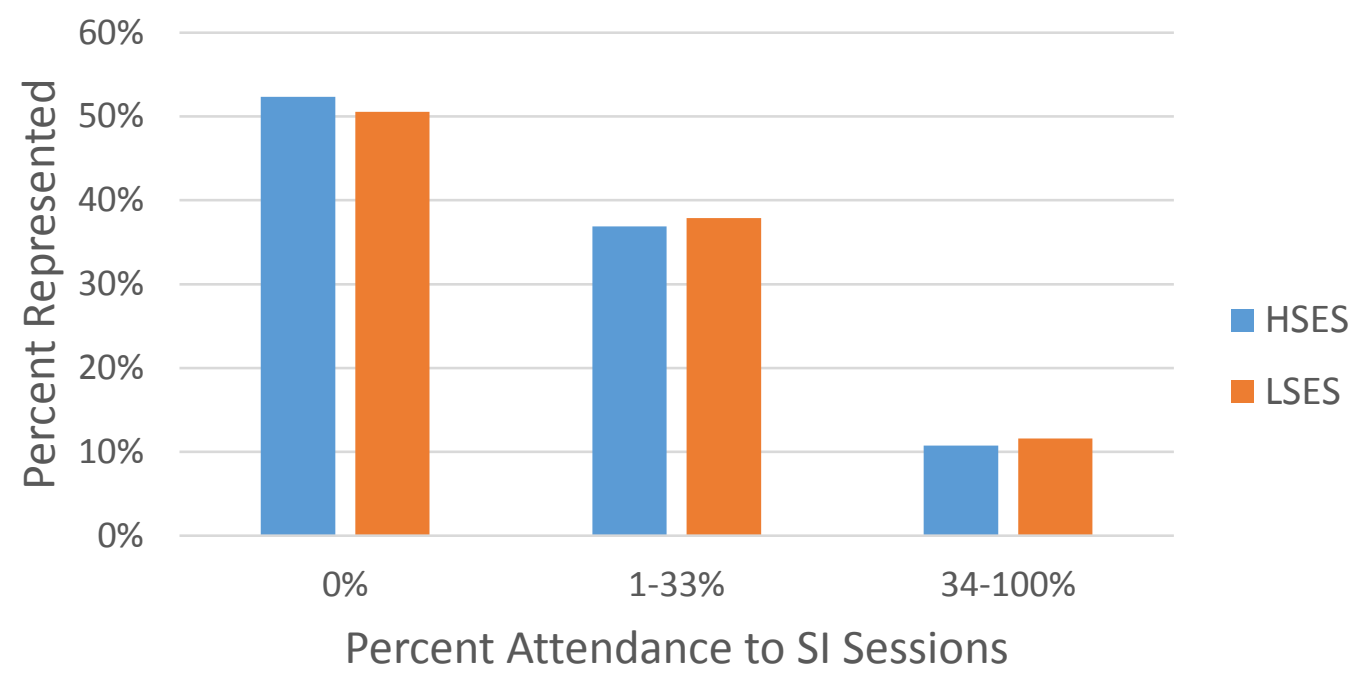

Figure 14 - Percent Attendance for LSES Students

Similarly to female students, students with LSES perform lower than their peers with no participation in SI (Figure 15). However, with SI attendance approaching 100\%, LSES students begin to outperform high-socioeconomic status (HSES) students. When students were placed in percent attendance bins, LSES students make large leaps in course performance; the initial gap in passing rates between these two groups of students is reduced from $9 \%$ to $2.8 \%$ with regular SI attendance (Figure 16). 


\section{Passing Rates for LSES Students}

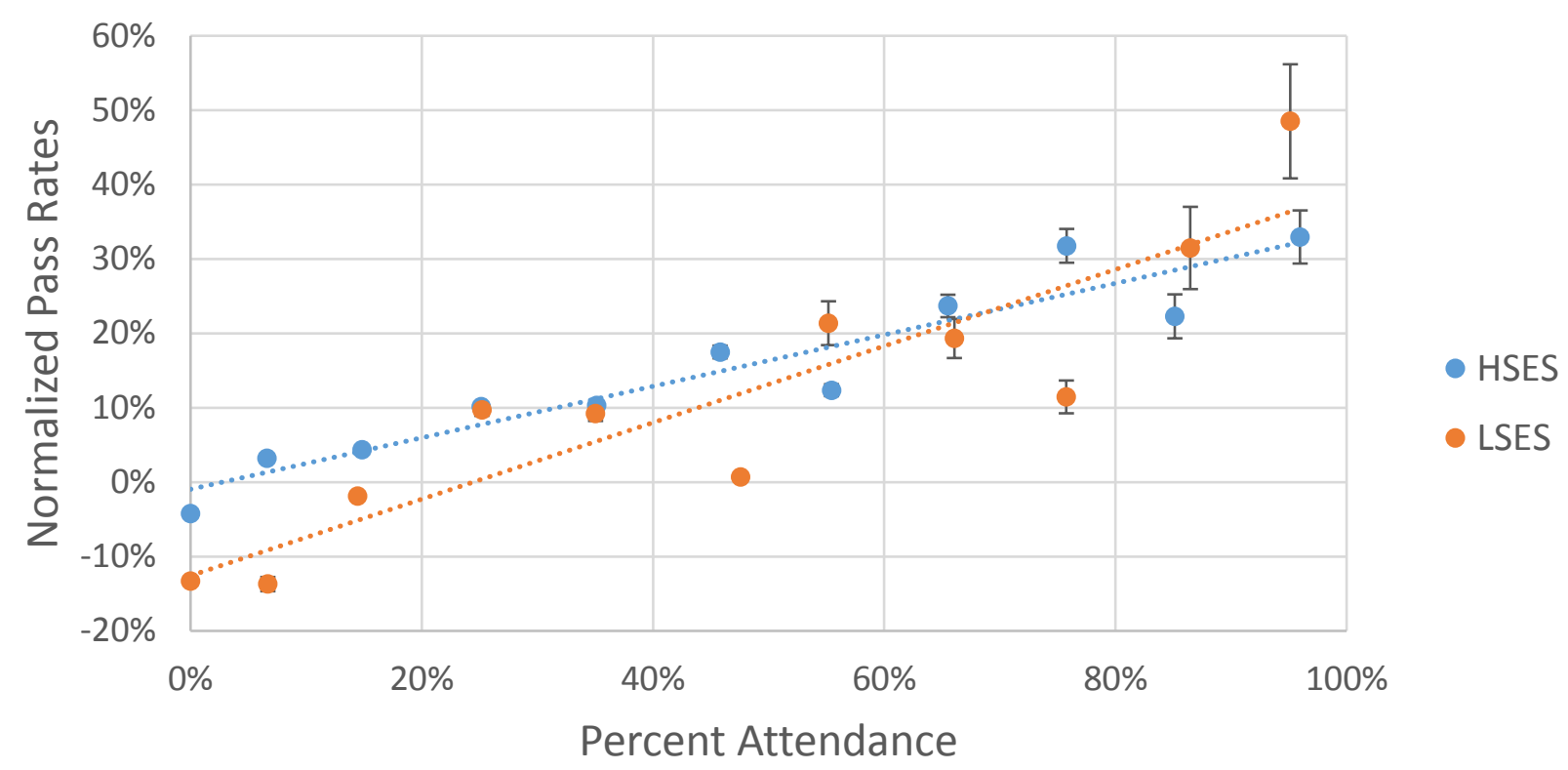

Figure 15 - Passing Rates for LSES Students

\section{Passing Rates for LSES Students}

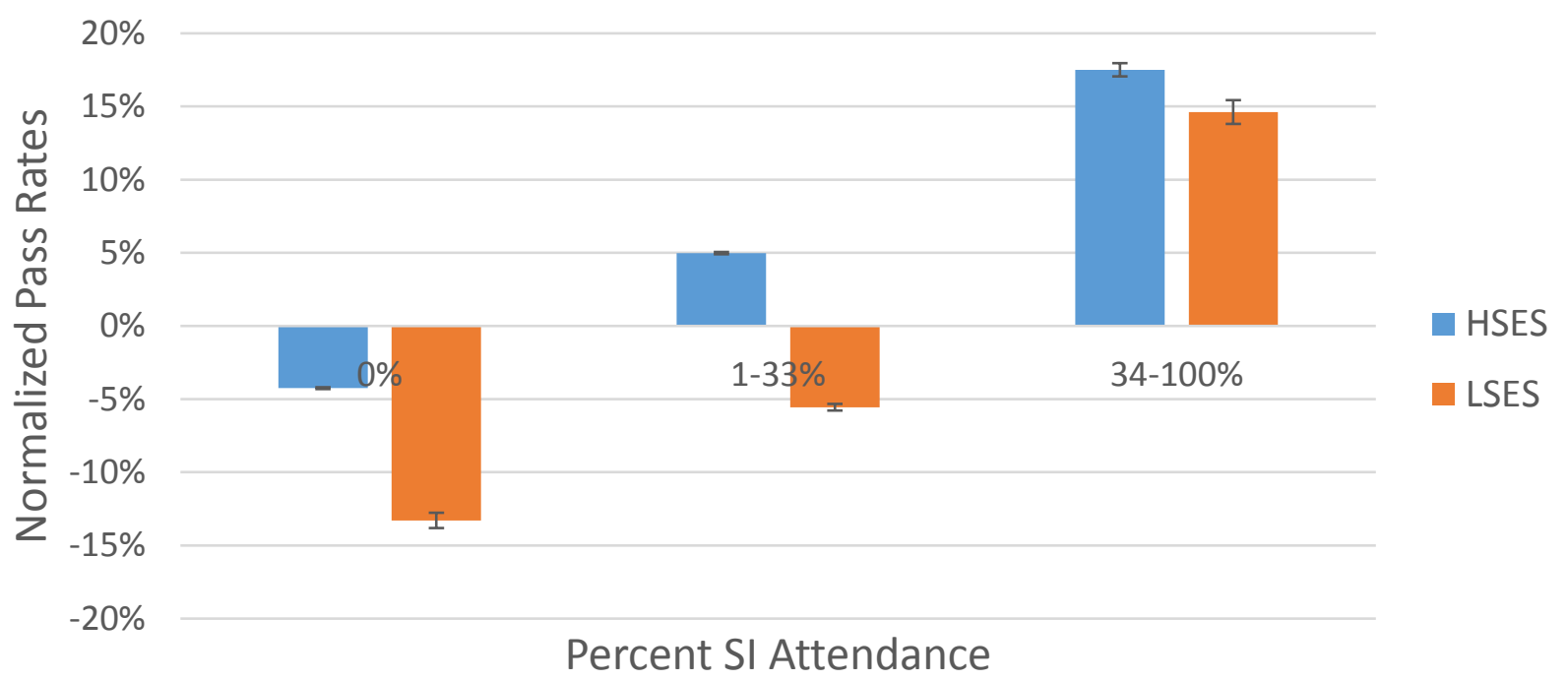

Figure 16 - Passing Rates for LSES Students in \% Bins of SI Attendance 
When analyzing MACT scores and academic preparation of LSES students, trends seem to resemble what was seen with females in Figures 12 and 13. LSES students tend to underperform HSES students at lower MACT ranges (0-24) while at moderate to higher MACT scores (25-36), there is little to no statistical difference observed. Independent of MACT score, the benefits of regularly using SI are still clear, as all groups performed above average.

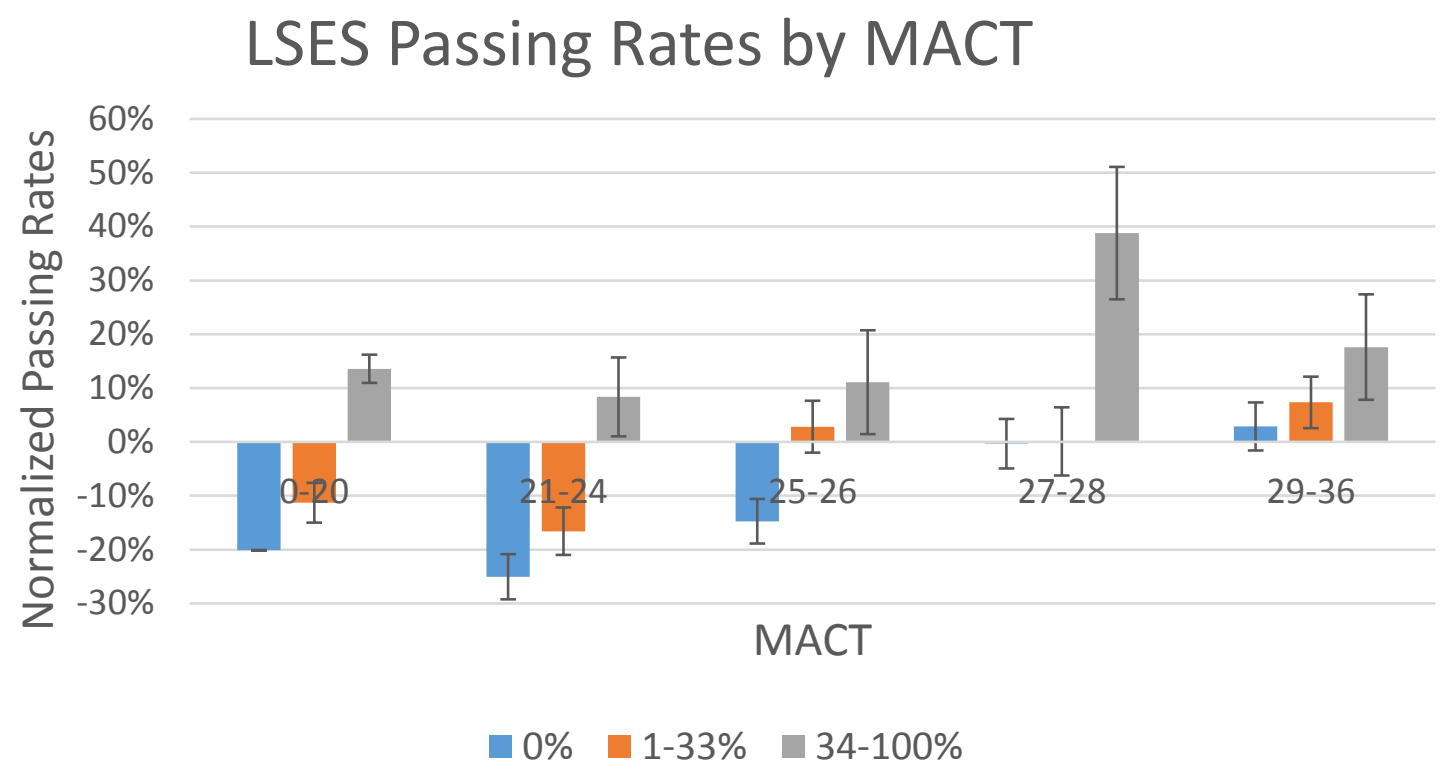

Figure 17 - Passing Rates for Low Socioeconomic Students with SI Attendance by Math ACT

\section{HSES Passing Rates by MACT}

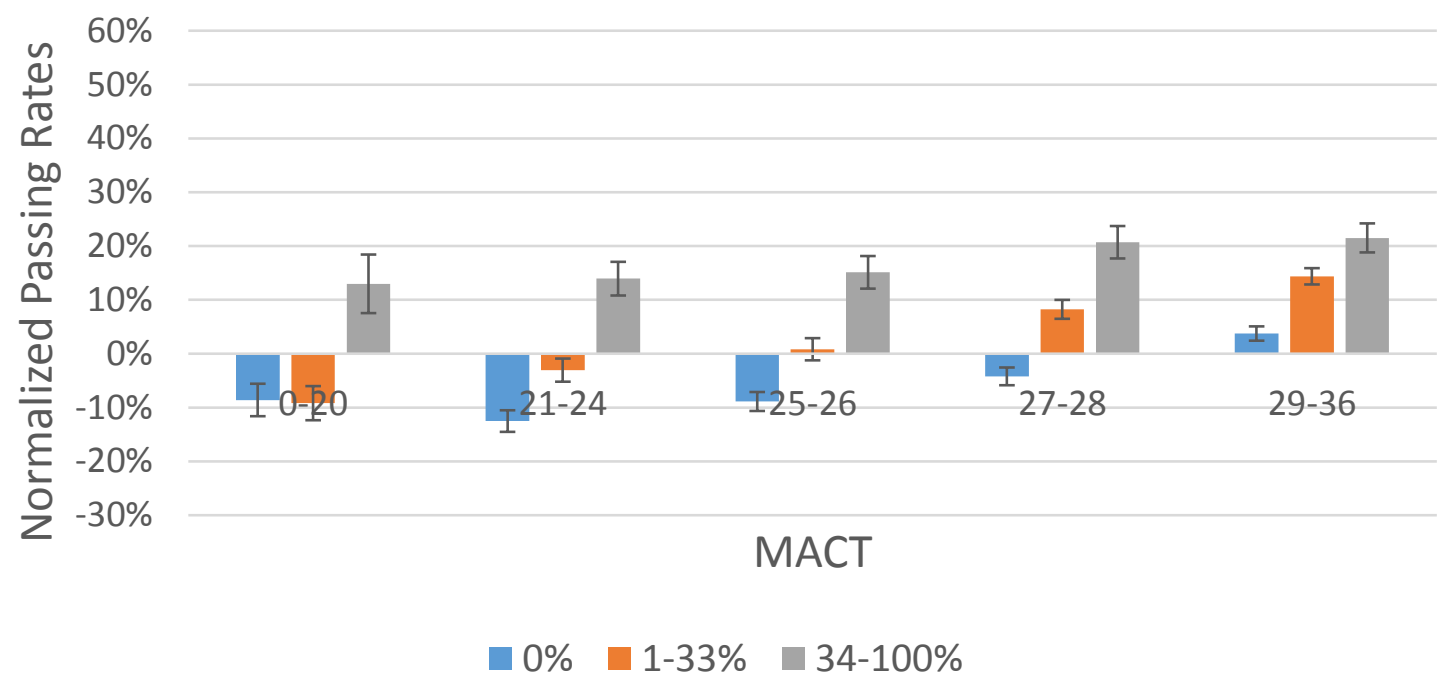

Figure 18 - Passing Rates for High Socioeconomic Students with SI Attendance by Math ACT 


\subsection{Minority Cross-Group Examination}

What about the overlap between students who fit into multiple underrepresented groups? Little difference is found between the gender minority and the ethnic minority, with $4.2 \%$ of the population being female and of an ethic minority. Further overlap is found when examining socioeconomic status. Figures 19 and 20 show students of low and high socioeconomic status broken down by ethnic minority. In addition to the ethnic minority overlap, females make up $23.1 \%$ of LSES students and $16.1 \%$ of HSES students. The author recognizes that there is overlap and a multivariate analysis will be further pursued to determine the dominant factors leading to performance.

\section{LSES Student Composition}

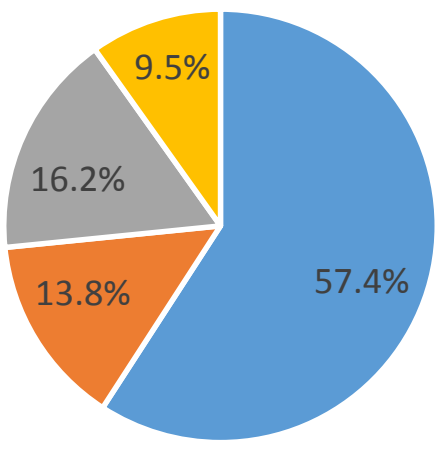

White $\quad$ Asian $\quad$ Black or African American $\quad$ Hispanic or Latino

Figure 19-Ethnicities of Students Considered to Be of Low Socioeconomic Status

\section{HSES Student Composition}

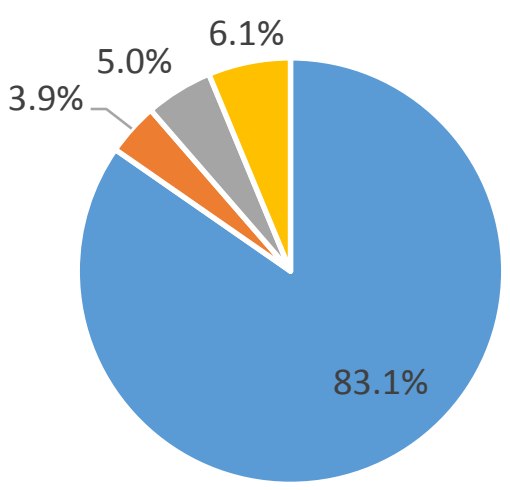

- White $\quad$ Asian $\quad$ Black or African American $\quad$ Hispanic or Latino 


\section{Discussion}

Studies that view the success of supplemental instruction programs are nearly all positive to varying degrees, and LSU has been no different with students who attend SI regularly being $23.2 \%$ more likely to pass a course compared to students who do not attend at all. Further analysis was needed to understand how SI affects different sub-groups of students and why it might affect them differently.

\subsection{Closing the Gap}

Females, ethnic minorities, and students with low socioeconomic status (LSES) all received higher benefits per SI session than their peers. One reason could be because females and ethnic minorities participate in SI at a higher rate than Caucasian males. SIs report that females actively participate more in sessions than males do; however, this would not explain the other groups. That doesn't explain the differences seen in students from different socioeconomic groups. Another explanation could be that even though these groups are gaining the same academic benefits as their peers, there are additional benefits in self-efficacy and other psychological factors. It is possible that through participatory design and inclusion, minority groups feel a sense of equality that may not be achieved without the interaction of SI. This could give students and added psychological benefit that boosts confidence. If confidence, and therefore self-efficacy are increased, there is a clear added benefit to these students which research supports $(11,12)$.

Based on discussions the authors had with several minority students, it is also possible that the peer role of the supplemental instructor plays is meaningful. It is possible that minority students feel more distanced from professors, as the majority of faculty members in the College of Engineering are Caucasian or Asian males with financial security. Due to the SI being a student, it is possible that this additional peer interaction means more to these groups and that they, therefore, appreciate this service more than majority students. This peer role is also independent of whether the SI is a part of a minority group because the SI is a fellow undergraduate student in the same age range of most SI attendees.

Surveys are handed out at the end of each semester in all classes in which SI is offered. Results from the surveys indicate tremendous positive support of the program with only $\sim 5 \%$ of responses being critical or negative. Comments from students often include that the Supplemental Instructor is effective because they teach material in a way that undergraduate students understand. Many students have directly stated in the surveys that they appreciate that the SI is a peer and understands the struggles they are going through. These surveys support the theory that the addition of peers in the learning process can give benefit beyond just academic preparation, regardless of the SI's ethnicity/gender/socioeconomic status.

\subsection{Academic Preparation's Influence on Minority Students}

The motivations needed to achieve success in engineering between ethnic minorities and female students can vary wildly. The literature points towards female students being affected by subconscious, negative self-perceptions ${ }^{(22,23,24)}$. Based on the author's findings, it seems that this is not the entire story, especially for ethnic minorities. Research that has been previously 
conducted regarding the need for ethnic minorities to increase their academic indexes has only included African-American and Hispanic students; literature on Asian students is lacking (6, 21). For the same level of academic preparedness (using Math ACT as the best predictor), minority students underperformed compared to the majority. African American and Asian students who did not attend SI never reached the course average for all levels of academic preparedness while Hispanic students only surpassed the average when MACT became higher than a 30. These results for ethnic minority students are distressing and show more depth to the problem than initially thought. Since prior academic knowledge does not seem to play as big of a factor as predicted, the authors' hypothesis is that the differences in these results most likely stems from underlying subconscious views of how each ethnicity believes they fit into engineering. Female students underperformed compared to male students at lower levels of academic preparation, but then began to outperform at higher Math ACT score (27-36). The same trend is found in students with low and high socioeconomic status.

Therefore, it is possible that self-efficacy is important for ethnic minority students at all levels and is important for female and LSES students at lower levels of academic preparation. This implies that ethnic minority students may have self-efficacy issues across the board, and this should be a point of concern no matter how prepared one might think an ethnic minority student is. Females and LSES students may only have self-efficacy issues when told through testing and scores that they are at or below average; however, when test scores give positive reinforcement saying that they are performing above the average, they become significantly more self-proficient and, in the case of females, perform higher than males.

While the gaps found between all minority students are crucial to understand so that problems may be addressed in technical areas of higher education, it is also essential to understand that all groups received significant benefit from SI. The differences between attending SI regularly verses not attending at all are: $21.4 \%$ (Caucasian), 35.9\% (African American), 23.5\% (Hispanic), 31.9\% (Asian), 22.2\% (Male), 26.7\% (Female), 21.8\% (HSES), and $26.6 \%$ (LSES) when averaged across all engineering classes. SI still gives significant benefit to all groups when students attend sessions regularly.

\subsection{Who is Attending SI?}

Another interesting trend is minorities and females being more likely to utilize SI than their peers. This could stem from these students feeling like they have a lesser chance of becoming an engineer due to subconscious views on engineering being a Caucasian-male dominated field and, therefore, have a higher desire to utilize programs that will make them more likely to succeed. It could also be for reasons mentioned previously about these students needing a more relatable figure to assist/teach the course.

One note about attendance from previous findings indicated that students utilizing SI at the highest rates were students who were least likely to pass the course initially ${ }^{(18)}$. This trend remained true for all groups represented except for Asian students. Asian students who attended sessions the most were already the most likely to succeed, whereas Asian students that did not attend sessions were already at a disadvantage. This is interesting that this ethnic minority is the only one to break the trend. There could be many possibilities, but it is the author's belief that this stems from the model minority belief that Asian students are expected to perform above 
average compared to their peers and therefore participate even at higher levels of academic preparation $^{(23,24)}$.

It was surprising that students of low socioeconomic status were able to attend SI at similar rates to high socioeconomic students since they are more likely to have more difficult schedules (many LSES students work part time to support themselves). The literature supports that LSES students are more likely to put their free time into tasks that will further their engineering career, which may certainly be an important factor for this trend ${ }^{(19)}$.

\section{Conclusions}

1. Ethnic minority and female students utilize SI at higher rates than their peers while lowsocioeconomic students utilize SI at similar rates as their peers.

2. Ethnic minority, female and low-socioeconomic students all receive more benefit per session attended compared to their peers.

3. Gaps in performance for ethnic minority students not utilizing SI, with equal levels of academic preparation as non-minorities, are substantially large.

4. Academic preparation plays a smaller role at LSU in the prediction of ethnic minority students passing a course than current literature leads one to believe.

5. Females and LSES students underperformed compared to males and HSES students at lower Math ACT scores, with the trend reversing at higher Math ACT scores.

6. All minorities made staggering leaps in course performance between not utilizing SI and utilizing SI regularly: African American (35.9\%), Hispanic (23.5\%), Asian (31.9\%), Female (26.7\%), LSES (26.6\%).

7. All minorities performed higher than the course average when attending SI regularly: African American (7.7\%), Hispanic (15.2\%), Asian (17.6\%), Female (20.7\%), LSES $(14.6 \%)$.

Supplemental Instruction can now be counted as one of the many programs that successfully decreases the academic performance gap between ethnic minority students and Caucasians. This gap was decreased to within $3 \%$ of course averages for all groups excluding African Americans. One of the most surprising things about these findings is that the SI program was not designed to give additional benefit to minority, female, or low-socioeconomic students. Through active learning and inclusion, the SI program at LSU has shown to have a substantial impact on all populations of students

\section{References}

[1] E. Brothers, B. Knox, "Best Practices in Retention of Underrepresented Minorities in Science, Technology, Engineering, and Mathematics (STEM) in the Tennessee Louis Stokes Alliance for Minority Participation (Tennessee LSAMP),” Journal of Intercultural Disciplines, vol. 11, 2013.

[2] A. Camacho, D. Hum, "Measuring the Effectiveness of an Intensive Math Preparation Program to Enhance the Success of Underrepresented Students in Engineering," Proceedings of the 2016 ASEE Annual Conference, New Orleans, LA, June 2016. 
[3] Felder, R., Brent, R. (2009). Active Learning: An Introduction. ASQ Higher Education Brief, 2(4) August 2009. Retrieved January 31, 2015 from http://www4.ncsu.edu/unity/lockers/users/f/felder/ public/Papers/ALpape r\%28ASQ\%29.pdf

[4] C. Wilson, A. Steele, W.Waggenspack, and W. Wang, "Engineering Supplemental Instruction: Impact on Sophomore Level Engineering Courses," Proceedings of the 2015 ASEE Annual Conference, Seattle, WA, June 2015.

[5] C. Wilson, W. Waggenspack, A. Steele, J. Gegenheimer, "The Unsubstantiated Cutoff: Deeper Analysis of Supplemental Instruction Sessions on Engineering Courses," Proceedings of the 2016 ASEE Annual Conference, New Orleans, LA, June 2016.

[6] "Encouraging Minority Students to Pursue Science, Technology, Engineering and Math Careers," U.S. Commission on Civil Rights, October 2010.

[7] C.R. Crumb, B. King, "Questioning a White Male Advantage in STEM: Examining disparities in College Major by Gender and Race/Ethnicity," Educational Researcher, vol. 39, no. 9, 2010.

[8] K. Bowman, "Engineering Degree Trends for African American Women and Men," Proceedings of the 2015 ASEE Annual Conference, Seattle, WA, June 2015.

[9] L. Bottomley, K. Titus-Becker, "Assessing the Success of Programs for Women in Engineering," Proceedings of the 2015 ASEE Annual Conference, Seattle, WA, June 2015.

[10] J. White, G.H. Massiha, "The Retention of Women in Science, Technology, Engineering, and Mathematics: A Framework for Persistence," International Journal of Evaluation and Research in Education, vol.5, no. 1, 2016.

[11] D. Baker, L. Wood, J. Corkins, S. Krause, "Tinkering and Technical Self-Efficacy of Engineering Students at the Communicty College," Community College Journal of Research \& Practice, vol. 39 , no. 6, 2015.

[12] A. Lourens, "The Development of Co-Curricular Interventions to Strengthen Female Engineering Students' Sense of Self-Efficacy and to Improve the Retention of Women in Traditionally MaleDominated Disciplines and Careers," South African Journal of Industrial Engineering, vol. 25, no. 3, 2014.

[14] K. Donaldson, G. Lichtenstein, S. Sheppard, "Socioeconomic Status and the Undergraduate Engineering Experience: Preliminary Findings from Four American Universities," Proceedings of the 2008 ASEE Annual Conference, Pittsburg, IN, June 2008.

[15] C. Adelman, "Principal indicators for student academic histories in postsecondary education, 19722000,” U.S. Department of Education Institute of Education Sciences, 2004.

[16] S.L. Thomas, and L.W. Perna, "The opportunity agenda: A reexamination of postsecondary reward and opportunity, in Higher education: Handbook of theory and research," J.C. Smart, Editor. 2005, Kluwer Academic Publishers: The Netherlands. p. p. 43-84.

[17] S. Conrad, S. Canetto, D. Macphee, S. Farro, "What Attracts High-Achieving Socioeconomically Disadvantaged Students to the Physical Sciences and Engineering," College Student Journal, vol. 43, no. 4, 2009. 
[18] C. Corbett, C. Hill, and A. St. Rose, "Where the Girls Are: The Facts About Gender Equity in Education," American Association for University Women Educational Foundation, Washington, D.C., 2008.

[19] M. Orr, N. Ramirez, M. Ohland, "Socioeconomic Trends in Engineering: Enrollment, Persistence, and Academic Achievement," Proceedings of the 2011 ASEE Annual Conference, Vancouver, British Columbia, June 2011.

[20] U.S. Department of Education, Federal TRIO Programs Current-Year Low-Income Levels, January 25,2016

[21] M. Ing, C. Victorino, "Differences in Classroom Engagement of Asian American Engineering Students," Journal of Engineering Education, vol. 105, no. 3, 2016.

[22] C. Steele, "Whistling Vivaldi," W.W. Norton \& Company, New York, 2010

[23] Y. Ma, "Model Minority, Model for Whom? An Investigation of Asian American Students in Science/Engineering," AAPI Nexus, vol. 8, no. 1, 2010.

[24] D. Trytten, A. Lowe, S. Walden, “'Asians are Good at Math. What an Awful Stereotype': The Model Minority Stereotype's Impact on Asian American Engineering Students," Journal of Engineering Education, vol. 101, no. 3, 2012. 